\title{
Physiotherapy and Occupational Therapy in Acute Neurology
}

\section{(ㄷ) (1) (우)}

Authors

Rüdiger J. Seitz¹, 2, Aschwin Kolman¹, Birgit Kraft-Kornwinkel1, Sabine Robbers

\begin{abstract}
Affiliations
1 Department of Neurology, Center of Neurology and Neuropsychiatry, LVR-Klinikum Düsseldorf, Medical Faculty, Heinrich-Heine University Düsseldorf, Düsseldorf, Germany

2 Florey Neuroscience Institutes, Melbourne, Australia
\end{abstract}

Key words

physiotherapy, occupational therapy, scales, therapeutic goals, stroke unit

Correspondence

Prof. Dr. med. Rüdiger Seitz

Abteilung Neurologie

Zentrum für Neurologie und Neuropsychiatrie

LVR-Klinikum Düsseldorf

Medizinische Fakultät

Heinrich-Heine-Universität Düsseldorf

Bergische Landstrasse 2

40629 Düsseldorf

Germany

seitz@neurologie.uni-duesseldorf.de

\author{
Bibliography \\ DOI http://dx.doi.org/10.1055/s-0044-100228 \\ Neurology International Open 2018; 2: E108-E117 \\ (c) Georg Thieme Verlag KG Stuttgart · New York \\ ISSN 2511-1795
}

\section{ABSTRACT}

Therapy of neurological patients comprises, beyond medical treatment, the treatment of functional deficits which result from a neurological disease such as stroke. Physiotherapy aims at enabling bedridden neurological patients to become mobile again using training of movement and coordination. In cooperation with occupational therapists, patients are trained to become able to perform activities of daily living again. In addition, multimodal activating/assisting exercises are mandatory to counteract the deficit-related development of joint contractures. The rationale for these exercises are neurophysiological findings about postlesional cerebral plasticity. Moreover, parametric scales have been developed to assess neurological disturbances and to monitor their resolution in an observer-independent fashion. This allows communication across institutions and to assess the efficacy of physiotherapy and occupational therapy.

\section{Introduction}

Neurological disorders are associated with impaired motor function, including paresis, so-called extrapyramidal signs, such as spasticity and rigidity, and impaired sensorimotor control and movement conception. Physiotherapy and occupational therapy complement the medical treatment of neurological patients by helping patients on the behavioral level to overcome disease-related functional impairments. In the past, neurological patients with motor impairments were treated with therapies based on outdated concepts (Bobath, proprioceptive neuromuscular facilitation (PNF)), inducing synergistic movement patterns with the help of therapeutic stimuli [1]. By contrast, the core element of modern, neuroscience-based treatment approaches is active, repetitive training of a defined movement or movement sequence. For this purpose, "isolated sensorimotor training" and "task-oriented training" are used [2-4]. According to experimental studies, these exercises can be supported by rhythmic acoustic stimulation [5], bilateral training [6] as well as motor imagery [7] and mirrored movement observation $[8,9]$. With this approach, the restoration of motor skills after injuries to the nervous system is understood as a motor learning process based on the plasticity of the brain [10-12].

Neurological departments are dedicated to the diagnosis and management of acute neurological conditions, such as stroke and inflammatory diseases of the nervous system, e. g., multiple sclerosis and Guillain-Barré syndrome, as well as to providing in-patient care, including differential diagnostic assessments and specialized therapies, for patients with chronic neurodegenerative diseases, such as normal pressure hydrocephalus and Parkinson syndromes. During the hospital stay, the key element of patient management is pathogenesis-oriented drug or interventional therapy [13]. In addition, functional impairments resulting from neurological disease are treated with physiotherapy and occupational therapy according to their clinical impairments. While motor learning and the processes involved in postlesional plasticity of the brain are long-term in nature, the mean duration of a stay on a neurological ward in Germany is currently only 6 days [14]. Conse- 
quently, the timeframe of hospitalization during which physiotherapy and occupational therapy can be administered and possibly show effect is very short.

Since physiotherapy and occupational therapy require significant staff resources, the health economic question arises whether these treatment modalities should still be offered in acute neurology. Furthermore, neurophysiological and clinical studies have shown that the process of functional recovery, e. g., after ischemic stroke, can be very dynamic during the first few days, due to reperfusion, regression of secondary processes, such as disappearance of concomitant vasogenic cerebral edema, and perilesional molecular remodeling $[11,12]$. Because of this so-called spontaneous recovery, it is difficult to quantify the effects of physiotherapy and occupational therapy. In contrast, it is undisputed that at later stages of the clinical course intensive physiotherapy and occupational therapy-as provided in rehabilitation facilities during stays of up to several weeks-do have a therapeutic effect [1-4]. From a clinical perspective, it is still necessary to quickly mobilize the neurological patients and help them to return to a state where they can live independently and are capable of participating in activities of daily living. In addition, it is necessary to comprehensively document improvements in patient status during recovery/deficit-oriented physiotherapy and occupational therapy as objectively as possible to ensure optimal communication at the interfaces of care, for example at the transition from acute neurology to a rehabilitation facility. In view of the above, the current discussion of validated/evidence-based treatment methods in neurorehabilitation shall be extended to acute neurology.

\section{Tasks of Physiotherapy and Occupational Therapy}

The tasks of physiotherapy and occupational therapy differ between the neurological diseases. In patients with stroke, the primary goal is restoration of compromised function. Here, the aim of physiotherapy is to mobilize bedridden patients using active range-of-motion exercises in bed. If possible, patients are mobilized to sitting position and ultimately to standing position ( $\mathbf{F i g .} \mathbf{1}$ ). Subsequently, the patients' standing and walking abilities are trained with balance exercises. In addition, patients receive targeted training of fine motor skills. Here, occupational therapy exercises focus on the execution of activities relevant for daily living. Besides motor and sensory function, perception and cognition are trained with exercises focusing on the use of objects. Furthermore, multimodal active-assisted exercises help to prevent joint stiffness in limbs with restricted mobility. In bedridden patients, these exercises also help to prevent pneumonia and deep vein thrombosis. In patients with chronic neurological disease, by contrast, the goal is to record test-related or treatment-related improvements of a defined deficit, for example, improvements of gait associated with a "tap test" or treatment with dopaminergic medication in a patient with Parkinson's disease.

A characteristic feature of physiotherapy and occupational therapy is that a neurological deficit has to be identified and recorded before treatment can be applied. Thus, it is essential to compre- hensively record and clearly describe neurological deficits. Since motor function can only be determined during execution of movements, diagnosis and treatment very often make use of the same tasks. Since the therapists use their senses as measuring instruments, their respective level of experience is the basis for a differentiated diagnostic assessment and the choice of treatment. Thus, the therapist should support the patients in their movements as much as needed, but as little as possible, always strengthening the patients' confidence, for example, in standing and walking.

Here, a special challenge-in particular in a treatment team-is to record deficits as objectively and clearly as possible. This is critical for patient monitoring as it allows to provide evidence of functional improvements. Recently, disease-specific, but also deficitoriented metric scales have been developed for this purpose ( $\triangleright$ Table 1 ). The reason for the multitude of scales described in the literature is the fact that different scales have been created for the various diseases and research questions. However, whether the existing scales measure/record objectively and plausibly comparable parameters is subject to controversy. Nevertheless, calls for making evidence-based guidelines the basis for treatment decisions to improve quality in healthcare continue to become more widespread $[1,15]$. Guidelines offer healthcare professionals an opportunity to systematically apply scientific insights according to their evidence base [16-20]. Another aim is to record and improve the quality and efficiency of the work of healthcare professionals to increase transparency in clinical practice [17, 20,21]. Furthermore, this approach is used to reduce variability in the services provided by healthcare professionals and, in doing so, justify the services provided to external stakeholders, such as funding agencies [15].

Examples of objective and valid methods to assess performance limitations due to functional impairments include the Tinetti test [22] and the DEMMI test [23]. These scales are designed to help record the extent to which the ability to stand and to walk has been restored in a patient after treatment. As the result of validation studies, these (and comparable) tests using semiquantitative metric scales ( $\triangleright$ Table 1 ) have been published in recent years as a basis for national and international guidelines. For example, the German Society of Neurorehabilitation (Deutsche Gesellschaft für Neurorehabilitation, DGN) developed a clinical (S2e) guideline on the rehabilitation of mobility after stroke which describes target parameters [24]. With a similar intention, the Royal Dutch Physiotherapy Association (KNGF) created a guideline, supporting the use of outcome measures at defined time points and interventions with proven effectiveness and prognostic determinants in daily practice [25]. Key aspects of these guidelines include task-specific and setting-specific training scenarios in combination with treatment methods, such as Bobath, Affolter, Brunnstrom or PNF [1, 25], which are still in widespread use, but based on outdated concepts. Even though it is unlikely that these guidelines can be fully applied to patient groups in an acute neurology setting, including stroke units, some insights and principles may well be used to quickly restore the original functional and performance status in patients even during a very short treatment episode, taking into account the patient's general health status. To achieve this, however, it is necessary to first define treatment goals. 


\section{Existing information about patient \\ Reading of medical report, findings of medical physical examination, findings of other therapists, nursing care reports}

2. First contact, medical history and examination findings

Assessment of general condition based on the following parameters:

- Is the patient alert, responsive or does he show reduced alertness?

- How is the cognitive condition? Can the patient answer adequately and perform requested tasks?

- How is his/her speech?

Medical history and recording of present complaints:

- What has happened? What impairments are present?

- Had the patient already experienced ADL problems/difficulties in walking prior to the event? Has the patient used aids?

- Does the patient have other relevant diseases or did he/ she undergo surgery, resulting in functional impairments/ impaired mobility?

\section{Differentiation of impairments \\ The information obtained so far determines the further examination.}

1a In case of intracerebral hemorrhage, decreased alertness or within 24 hours after thrombolysis, patients are examined in the lying position:

- Passive joint mobility and pain on movement

- Muscle tone

- Active/active-assistive movements

- Active joint mobility

- Finger fine motor skills, including finger-thumb opposition

- Ataxia/coordination

- Heel-to-knee-to-shin test, finger-to-nose test,

- Target movements: reaching/grasping

- Somatosensory system

- Touch, graphesthesia, temperature, pain

- Proprioception/position mirroring

\section{Assessment/method}

\author{
Assessment/method \\ Glasgow Coma Scale [46] \\ Likert scale with 3 items \\ Moca test [47] \\ Descriptive
}

Descriptive

Since when?

Which and since when?

\section{Assessment/method}

\begin{tabular}{|l|l|l|l|l|l|l|}
\hline & \multicolumn{2}{|c|}{$\begin{array}{c}\text { Range of } \\
\text { Motion } \\
\text { yes/no }=x^{\circ}\end{array}$} & \multicolumn{2}{|c|}{$\begin{array}{c}\text { Pain } \\
\text { VAS/NRS } \\
0-10^{*}\end{array}$} & \multicolumn{2}{|c|}{$\begin{array}{c}\text { Tone } \\
\text { MAS** }\end{array}$} \\
\hline Shoulder & L & R & L & R & L & R \\
\hline Elbow & & & & & & \\
\hline Wrist & & & & & & \\
\hline Hip & & & & & & \\
\hline Knee & & & & & & \\
\hline Ankle & & & & & & \\
\hline
\end{tabular}

${ }^{*}$ Visual analog-scale, numeric rating scale,

**MAS = modified Asworth scale [48]

\begin{tabular}{|l|l|l|}
\hline & \multicolumn{2}{|c|}{$\begin{array}{c}\text { Impaired } \\
\text { yes/no }=\mathrm{x}^{\circ}\end{array}$} \\
\hline Shoulder & $\mathrm{L}$ & $\mathrm{R}$ \\
\hline Elbow & & \\
\hline Wrist & & \\
\hline Hip & & \\
\hline Knee & & \\
\hline Ankle & & \\
\hline
\end{tabular}

\begin{tabular}{|l|l|} 
& 3-point Likert scale $\rightarrow$ good/moderate/poor \\
\hline Arm & \\
\hline Leg & \\
\hline
\end{tabular}

Fig. 1 First contact and formal assessment by therapist. 
1b With possibility of mobilization in bed

- Mobility in bed

- Active movements/development of strength

2 With possibility of mobilization:

- Mobilization of patient to sitting position

- Postural stability

With good stability:

- Active/active-assistive movements

- Active movements/development of strength

- Finger fine motor skills, including finger-thumb opposition

- Ataxia/coordination

Heel-to-knee-to-shin test, finger-to-nose test,

Target movements: reaching/grasping

- Mobilization of patient to standing position

- Assessment of standing position

- Assessment of gait
Trunk control test items $1+2$ [49] or DEMMI items $1+2$ [23]

\begin{tabular}{l|l|l|l|l|} 
& \multicolumn{2}{|c|}{$\begin{array}{c}\text { Degree of strengths } \\
\text { (MRC) Lying }\end{array}$} & \multicolumn{2}{|c|}{$\begin{array}{c}\text { Motricity Index } \\
\text { Sitting }\end{array}$} \\
\hline Shoulder & L & R & L & R \\
\hline Elbow & & & & \\
\hline $\begin{array}{l}\text { Wrist/ } \\
\text { precision grip }\end{array}$ & & & & \\
\hline Hip & & & & \\
\hline Knee & & & & \\
\hline Ankle & & & & \\
\hline
\end{tabular}

Trunk control test item 4 [49] or DEMMI item 3 [23]

Trunk control test item 3 [49] or DEMMI item 4 [23]

3-point Likert scale $\rightarrow$ good/moderate/poor or $\rightarrow$ bradykinesia

\begin{tabular}{|l|l|l|l|l|}
\hline & \multicolumn{2}{|c|}{$\begin{array}{c}\text { Degree of strengths } \\
\text { (MRC) Sitting }\end{array}$} & \multicolumn{3}{|c|}{$\begin{array}{c}\text { Motricity Index } \\
\text { Sitting }\end{array}$} \\
\hline Shoulder & L & R & L & R \\
\hline Elbow & & & & \\
\hline $\begin{array}{l}\text { Wrist/ } \\
\text { precision grip }\end{array}$ & & & & \\
\hline Hip & & & & \\
\hline Knee & & & & \\
\hline Ankle & & & & \\
\hline
\end{tabular}

DEMMI items 5+6 [49] or Berg Balans Scale Item [50] Time-up and go test [51], 10-meter walking test [51], gait UPDRS [52]

Fig. 1 Continued.

\section{Note}

In acute neurology, physiotherapy and occupational therapy shall help patients to overcome their functional deficits as well as to record the improvement of impairments using suitable scales.

\section{Goals of Treatment}

In the acute phase of a neurological disease, the treatment goals of physiotherapy and occupational therapy are defined by the severity of the functional deficit, while the disease-specific pathogenesis of the respective neurological disorder, which determines the medical management, is of secondary importance. The aim of physiotherapy and occupational therapy interventions is the ultimately complete restoration of the patient's ability to live independently. Therefore, early goals, focusing on the fastest possible recovery from functional neurological deficits, are at the center of these interventions. The early treatment goals are directed on both physical mobility and arm-hand function addressing the individual needs of the patients ( $\bullet$ Fig. 1). Sequential subgoals are defined and then addressed successively in a diagnostic and at the same time therapeutic fashion in severely impaired or even bedridden patients who have the potential to be mobilized ( $\vee$ Table 2 ). A number of tests with various semiquantitative metric scales have been developed and validated for clinical use to standardize and objectify diagnostic assessments and make these comparable, e. g., when following-up patients. Some basic, easy-to-use and validated tests to assess various aspects of body control in neurological patients are compiled in $>$ Table 1.

It should be noted in particular that, besides therapeutic instructions, the therapist's verbal feedback is crucial for successful treatment. This applies to the complete course of treatment inter- 
- Table 1 Mobilization strategy for bedridden neurological patients, including patients on stroke-unit.

1. Verbal contact

2. Tactile contact

3. Active-assistive movements/passive movements

4. Arm function exercises

5. Mobilization to sitting on the edge of the bed

6. Mobilization to standing position in front of bed

7. Mobilization to walking

8. Balance exercises

Strategic pathway: $\rightarrow$ supine position $\rightarrow$ side position $\rightarrow$ sitting position

$\rightarrow$ standing position $\rightarrow$ ambulation

Note:

$1-4$ for initial examination

3-8 serve both diagnostic and therapeutic purposes

5-8 In stroke patients with thrombolysis only after a hemorrhage has been ruled out and blood pressure control has been achieved

ventions, starting with mobilization in bed, mobilization at the edge of the bed, followed by mobilization to standing position, and finally ambulation. Examples for such measures, which can be varied among each other, are listed in $>$ Table 3 . In addition, physiotherapy and occupational therapy interventions targeted at improving hand function should be started as early as possible to restore the patient's ability to independently perform manual activities ( Fig. 1, - Table 3). Occupational therapy focusses on planning, performing and perceiving activities of direct benefit to the patient, such as picking up the toothbrush, taking it to the mouth and performing oral hygiene. With patients understanding that these activities increase their autonomy and promote their independence, their intrinsic motivation to actively participate in the training is stronger. It should be noted, however, that patients with good practice or functional status prior to the start of the neurological disease recover their functional abilities faster and presumably achieve a better functional status compared to patients with no prior training.

On a stroke unit, impairments of consciousness, hemodynamic stability and cardiorespiratory reserve are important factors limiting patient mobilization out of bed [26]. In addition, it should be taken into account that mobilization of stroke patients, especially out of bed, is only included in the treatment options after blood pressure stabilization and exclusion of hemorrhage. For the management of patients in intensive care units and similarly stroke units, three key clinical domains for the treatment with physiotherapy and occupational therapy were identified in evidence-based recommendations: criteria to initiate physiotherapy treatment, clinical assessments of the various services provided and evidence for effectiveness of treatment [27]. Especially in patients severely affected by stroke, the following negative prognostic factors are predictive of severe functional impairments or even death: advanced age, female gender, atrial fibrillation, pre-stroke long-term nursing care, neuropsychological deficits, seizures, delirium or psychosis as well as pneumonia and tracheobronchitis [28].
> Table 2 Goals of treatment.

\section{Mobility of the body}

1.1. Independent change of position in bed; turning over, sliding back and forth

1.2. Postural stability when sitting with and without support by feet on the floor

1.3. Mobilization to stable standing position

1.4. Mobilization from stable standing position to independent ambulation

2. Manual abilities

2.1. Hand-object interaction (touching objects)

2.2. Grasping objects

2.3. Hand-mouth transfer

2.4. Bimanual synergies (washing, spreading butter on bred, opening and closing can)

2.5. Strengthening of shoulder-arm muscles

3. Independence (recording with COPM [53])

3.1. Self-sufficiency

3.2. Leisure activities

3.3. Productivity

\section{Note}

The goals of treatment are restoration of mobility and manual skills to enable the patient to live as independently as possible.

\section{Discussion}

In neurology, physiotherapy and occupational therapy are key areas of patient management, complementing medical treatment. The goal of these therapies is to restore the ability in patients with neurological deficits to independently perform activities of daily living and to participate in social life. Physiotherapy and occupational therapy complement each other. It should be noted that in neurological practice, speech therapy and neuropsychology play an important role as they extend the range of possible treatments. Speech therapy focuses on improving speech comprehension and speech production and on assessing and safeguarding active swallowing. The disturbances of neuropsychological functions, such as memory, attention (neglect) and action planning (apraxia), are trea ted by dedicated cognitive training programs. However, in this communication physiotherapy and occupational therapy are emphasized.

In acute neurology, priority is given to mobilization of the patient in bed, mobilization to sitting at the edge of the bed, progression to transfer to standing position, and finally to ambulation. This is complemented by restoration of arm-hand function so that the patient regains the ability to grasp objects and bring food to his mouth. In patients with cerebral infarction, intracerebral hemorrhage or acute relapses of multiple sclerosis, deficits with sudden onset have to be overcome. In patients with neurodegenerative diseases, for example from the spectrum of parkinsonian disorders, the ability to execute movements has to be restored and increasing disability due to disease progression has to be prevented. These 
- Table 3 Treatment interventions.

\section{Verbal contact}

- Speaking to the patient and improvement of alertness (opening eyes, verbal response)

" Can the patient tell his/her name? Is the patient oriented to place, time and situation?

- Assessment of comprehension and speech production

- Assessment of orientation and cognitive state

- Assessment of the patient's mental status

- What symptoms does the patient describe?

- Disturbances of higher brain functions?

- Signs of memory problems

- Signs of impaired disease awareness

- Signs of impaired action planning

- Signs of perception disorders, hallucinations

\section{Tactile contact}

- Through touch the patient becomes relaxed and more confident; the muscles of the affected limb are stimulated for the subsequent movements.

- Assessment of the somatosensory system (temperature, pressure, touch, pain, also graphesthesia and two point tactile discrimination with 1 or 2 fingers),

- Assessment of body awareness on the affected side (neglect) and directing the patient's attention to the affected side.

3. Active, active-assistive and passive movements (training against resistance)

- By the passive movement, the therapist obtains information about:

- Muscle tone of the extremities (fast or slow movement of large joints, such as knee or elbow)

- Mobility/range of motion of arms and legs

- Pain on movement

- Proprioception (mirroring with the healthy contralateral side)

- Need of treatment for prevention or avoidance of contractures (joint contractures lead to functional impairments)

- By active movements (initially on the healthy side), the therapist obtains information about:

- Can the patient perform the movement tasks adequately?

- Active-assistive range of motion in comparison to passive movements of arms and legs

- Bed mobility (bridging; change of position, including longitudinal mobility)

- Hand strength (vigor)

- Abnormal movement pattern (spasticity, associated movements)

- Pain report

- Proprioception and coordination (moving the heel of one leg down from the knee along the lower leg)

- Through movements against resistance the therapist obtains information about- the strength of the extremities

- The treatment goal is that the bedridden patient can perform a change of position in bed with only little assistance or even independently.
- Table 3 Continued.

\section{Arm function}

- Mobility: Active testing of the mobility of arm, hand and fingers. Passive movements are unsuitable for the treatment of stroke patients as upon a lack of voluntary facilitation movements are not re-learned to be performed independently. Active-assistive exercises are necessary in high-grade paresis to avoid contractures, to maintain the existing range of motion, to increase blood flow, and to make the patient aware about the affected side. It is of particular importance that the patient can in addition to visual controllingthe affected arm (focusing the patient's attention onto the affected side) imagine the sequence of movements; this is known as multimodal, active-assistive therapy.

- Strength: Through movement against resistance scaled relative to his remaining ability to exert force, the patient is to perform isotonic exercise movements

- Tone: With respect to spastic hypertonia in the paralyzed extremities, it is important to treat the stroke patient as early as possible to entrain movements which counteract the spastic movement pattern.

- Pain: Potential complications of a paralytic arm include autonomic dystrophy of the hand, subluxation of the arm due to lack of activity and supporting function of the shoulder muscles, and frozen shoulder due to loss of arm mobility

- Sensory function: Touch (sharp, dull, area), temperature, pain, mirroring

- Coordination: Finger-to-finger test, finger-to-nose test, diadochokinesis, twisting of the hands or fingers around each other

- Fine motor skills: Individual finger movements, finger opposition movements

- The goal is the independent performance of manual activities of daily living:

1. Lead the arm with an object to the mouth (food, cup, tablets)

2. Carry out personal hygiene (getting dressed, teeth brushing, visiting the bathroom)

3. Use of assistive devices (glasses, hearing aid, walker)

4. Use of everyday items (toiletries, cutlery, tubes or unscrew bottles, use of a mobile phone, wind up a watch, insert thread into needle)

5. Mobilization of a bedridden patient to sitting at the edge of the bed

- The patient should via his/her healthy but also via his/her affected side (in a physiological sequence of motion $\rightarrow$ lateral position $\rightarrow$ supported lateral sitting $\rightarrow$ symmetrical sitting position) transfer from lying to sitting position. The therapist obtains information about:

- Changes of position and posture the patient is able to perform independently

- Stable, symmetrical sitting possible?

- Postural control

- The goal is that the patient can independently get up to sit on the edge of the bed.

- No stable sitting possible:Without postural control, selective movements of the trunk and the extremities are not possible.

- Facilitating of the symmetry of the body using exteroceptive (stroking, clapping shaking) and proprioceptive stimulation (pushing, supporting, weight shift)

- Tactile stimulation of the affected side, e. g., stroking with folded hands along the shin of the affected side towards the ankle.

- Using training against resistance at key points (pelvis and shoulder girdle, sternum, shoulder blades)

- Facilitating active support on the affected side (e. g., hand-over exercises) 


\section{- Table 3 Continued.}

- With good sitting stability:

- Formal testing of strength and movement speed of the extremities

- Strengthening exercises, if needed

- Examination of fine motor skills (functional activities of daily routine such as grasping a cup, unscrewing lids, combing hairs etc.)

- Instruction of the patient to perform targeted movement tasks (also movements across the midline, for instance, touching the fingertips of the therapist, placing)

- Examination of coordination (cross-over movements, e. g., bring together hand and knee of the opposite sides, finger-to-nose test, finger-to-finger test)

- Examination of apraxia by imitation and following instructions

6. Mobilization of the patient to standing position in front of the bed

- Pre-requisite for standing up is stable sitting, even if it is not yet symmetrical. The patient is requested to stand up. The therapist obtains information about:

- Can the patient stand up independently?

- How much assistance is needed?

- Where and what kind of problem does the patient experience? (objectively and subjectively)

- How does the patient stand? (symmetrical, stabile, secure, in balance, upright, knee and hips in extension etc.)

- The goal is the independent transition from sitting in bed to a chair next to the bed.

- Start with exercises in the standing world, then use playful elements (e. g., holding on to wall bars and transfer weight to the sides, weight bearing of the affected side)

- 1. The patient is unstable when standing:

- What is the cause of the instability (strength, asymmetric tone, balance, anxiety, reduced knee stability, pain, other primary disease)?

- Information about the mobility of the swinging leg (quality of the movement, targeted movement pattern, ataxic movement pattern, holding on, movement in balance)

- The patient shall touch the lower bar with one foot; in this way, the therapist obtains information about the stability in the supporting leg (involuntary bending or giving way of knee, co-contraction of antagonists?)

- Goal: To give the patient a sense of security with the help of aids, such as a walker or by putting hands on key points (pelvis, shoulder girdle)

- 2. The patient is stable when standing:

- How is the balance? (e. g., arm movements across the midline, swingingsmoothly in alternation, reaching far forward with the arms, cross-over movements, such as bringing hand and knee of the opposite sides together, toe stand, heel stand, one-leg stand possible?)

- Narrowbased stand possible with open and closed eyes? Tandem stand possible with open and closed eyes?

- Ataxia? (one-leg stand, Romberg's test, Unterberger's stepping test)
- Table 3 Continued.

\section{Mobilization to walking}

- If the patient is unsteady or has already used a walker, treatment is started with a walker. Assessed are:

- Position of the body's longitudinal axis

- Paresis (e. g., foot drop)

- Stride length (2-3 feet)

- Base width

- Weight-bearing time

- Stability of the supporting leg? (knee stability, Duchenne gait, Trendelenburg gait)

- Spastic leg movement with circumduction?

- Supporting leg phase $60^{\circ}$ and swinging leg phase $40^{\circ}$ with heel contact of the free leg?

- Arm swinging present (if the patient does not use a walker)

- Gait speed (average is 110-120 steps /min)

- Is it possible to increase the gait speed or does that lead to an unsteady gait?

- The goal is the facilitation of the foot lift in the swinging leg phase and stabilization of the supporting leg phase

\section{Balance exercises}

- For testing the steadiness and balance during walking, examination of gait variations (tightrope walking gait, sideward steps, crossover steps, backwards gait, fast turns with change of direction) is used.

- According to the functional impairment of the patient, the problem will be addressed selectively and playfully (e. g., with a narrow-based gait, the patient should lift the leg over a rod or visible line to the side to such an extent that the other leg fits next to it.)

- The goal is a steady, independent, preferably physiological ambulation with and without carrying objects.

- If the patient has difficulties with stability when standing or to keepbalance while standing, he/she should hold on to the wall bars or to the handrails and should shift weight while standing to either side, the front and the back.

- The patient shall (e. g., 10x each) lift one leg or the legs alternately onto the lower bar (proprioceptive input for the supporting leg and initiation foot lifting of the free leg)

- Alternately lifting the legs and walking on the spot as well as side-close steps

- The patient stands on one leg and moves the free leg back and forth (forth with heel contact and back with the tip of the foot)-> heel tip

- If the patient is standing in a stable posture (without holding on to anything), the arms can be used (swing exercise, targeted movement in different directions)

- Looking over the shoulder while standing

- Continuing with the exercises on the swing board, balance pad or uneven floor / mats

measures should already be initiated on the neurological ward during the few days of acute treatment and have to be continued and extended during the subsequent stay in a rehabilitation facility. There is good evidence that physical training should be integrated into the treatment plan of, for example, stroke patients as it contributes to successful secondary prevention with good survival chances [29]. Whether early mobilization after acute stroke improves the prognosis was evaluated in an international trial in which a trend indicative of a positive effect was found [30]. Further goals of treatment include moderate muscle activation, muscle development and reduced time spent in a sitting position as well as targeted secondary prevention of stroke [31]. 
To develop a suitable personalized set of exercises, therapists have to first identify which functional deficits are present in the patient and then tailor their exercises to these specific needs. This requires a differentiated examination covering all functional systems as known in clinical neurology. Similarly, the physiotherapist or occupational therapist performs a differentiated examination. In addition, therapists will evaluate whether their patients benefit from the treatment and whether their symptoms and functional impairments improve over the course of treatment. However, the description given a therapist is typically influenced by his/her expertise and not necessarily comparable with that of another therapist. Consequently, comparability of the examination method and documentation of findings is essential for the evaluation of changes in functional impairments along a time axis or across various patients. Against this background, various scales were designed to generate objective information about neurological functional impairments, especially in the field of neurorehabilitation. These semiquantitative scales serve the goal of standardizing examination findings to enable better comparisons of impairments between different patients within the treatment team, between different interventions and between different studies [32].

Surprisingly, a number of randomized multicenter trials failed to demonstrate relevant improvements with physiotherapeutic training methods [33,34]. Likewise, physiotherapy and occupational therapy showed no positive effect on parameters of quality of life in patients with Parkinson's disease [35]. The problem with large multicenter studies seems to be that in everyday clinical practice a number of factors, such as treatment approach, experience of the therapist team and changes in staff, lead to statistical noise which can conceal positive treatment effects [30]. By contrast, smaller monocentric studies demonstrated that the management of neurological patients does indeed benefit from the integration of specific training techniques [36]. For example, targeted training of hand extension did not only improve the trained function, but resulted in additional degrees of freedom for the hand which contributed to an overall improved hand function $[2,3]$. It is also known that certain functions, such as speed of gait, benefit from the extent of a specific gait training $[37,38]$. Thus, task-specific repetitive training seems to play a key role in physiotherapy, as it is similarly known from healthy persons learning new practical skills [1012]. Morevover, game-like animations have been developed to increase patient motivation for participating in repetitive training aimed at improving the function of the affected extremities $[39,40]$. In addition, occupational therapy aims at fostering patient participation. Therefore, the goals and consequently content of occupational therapy are directed at enabling the patient to live independently; with this treatment goal, the functional abilities of the affected extremity are improved.

Yet, there is an important pathophysiological aspect. Size and location of focal brain lesions, such as cerebral infarction, vary significantly between patients. Consequently, initial functional impairments observed in the acute phase after cerebral infarction and the dynamics of recovery may differ widely. The cerebral mechanisms of functional recovery are based on an interplay of various factors, including the extent of structural and functional recovery of the affected functional system, perilesional and interhemispheric plasticity and changes in cortical excitability $[41,42]$. Thus, recovery from, for example, hand/arm paresis varies widely with regard to extent and speed, even between patients with similar structural lesions [43]. Because of this variability, effects in individual patients may be concealed in group statistical analyses. For example, a blinded, randomized clinical trial found that more than 6 months after cerebral infarction specific task-related trainings effects were rather small and statistically insignificant [34]. Possibly, single-case time series are better suited to identify treatment effects irrespective of the interindividual differences [44]. Nevertheless, the important question remains as to whether the scales currently in use can differentiate between recovery of function and compensation of deficits.

As shown in $>$ Table 1, the aim should be to use validated methods to record standardized assessments and treatment follow-ups. For example, the DEMMI test for critically ill patients treated in intensive care units has proven to be a reliable instrument to assess mobility [45]. The test was developed when in the Netherlands evidence-based guidelines for critically ill patients were to be established. In order to achieve this, more than 129 relevant studies were prospectively evaluated in a meta-analysis and core criteria to be used as treatment criteria on intensive care units were identified. The insights derived from this type of research approaches should be applied to acute neurology and also validated. Here, the requirements should be that these tests are reliable, easy to use, quickly implemented and are valid. The therapist's focus should remain on treating patients; the treatment time available for the individual patient must not be compromised by time-consuming documentation of highly diversified test procedures. Thus, the challenge is to define treatment goals in everyday clinical practice and to record noticeable treatment effects in a standardized and comprehensible way. This has the advantage that functional impairments can clearly be communicated between medical facilities. Ultimately, this approach serves the purpose of proving the medical need for physiotherapy and occupational therapy treatments to the funding authorities.

\section{Conclusion for Clinical Practice}

Physiotherapy and occupational therapy are integral part of neurology, supporting patients in overcoming disease-related functional impairments. Using functional scales, treatment progress can be communicated within a treatment team and between healthcare institutions.

Conflict of Interest

No conflict of interest has been declared by the authors.

References

[1] Nelles G. Rehabilitation von sensomotorischen Störungen. AWMF Leitlinien 2012 http://www.awmf.org/leitlinien/detail/ll/030-123.htm1

[2] Bütefisch CM, Hummelsheim H, Denzler $P$ et al. Repetitive training of isolated movements improves the outcome of motor rehabilitation of the centrally paretic hand. J Neurol Sci 1995; 130: 59-68

[3] Hummelsheim $\mathrm{H}$. Rationales for improving motor function. Curr Opin Neurol 1995; 12: 697-701 
[4] Platz T, van Kaick S, Mehrholz ] et al. Best conventional therapy versus modular impairment-oriented training for arm paresis after stroke: A single-blind, multicenter randomized controlled trial. Neurorehabil Neural Repair 2009; 23: 706-716

[5] Thaut MH, McIntosh GC, Hoemberg V. Neurobiological foundations of neurologic music therapy: Rhythmic entrainment and the motor system. Front Psychol 2015; 5: 1185 doi:10.3389/fpsyg.2014.01185

[6] Mudie MH, Matyas TA. Responses of the densely hemiplegic upper extremity to bilateral training. Neurorehabil Neural Repair 2001; 15 : $129-140$

[7] Simmons L, Sharma N, Baron JC et al. Motor imagery to enhance recovery after subcortical stroke: Who might benefit, daily dose, and potential effects. Neurorehabil Neural Repair 2008; 22: 458-467

[8] Rothgangel AS, Braun SM, Beurkens A] et al. The clinical aspects of mirror therapy in rehabilitation: A systematic review. Int J Rehab Res 2011; 34: 1-13

[9] Dohle C, Püllen J, Nakaten A et al. Mirror therapy promotes recovery from severe hemiparesis: A randomized controlled trial. Neurorehabil Neural Repair 2009; 23: 209-217

[10] Seitz RJ, Matyas TA, Carey LM. Neural Plasticity as a basis for motor learning and neurorehabilitation. Brain Impairment 2008; 9: 103-113

[11] Cramer SC. Repairing the human brain after stroke: I. Mechanisms of spontaneous recovery. Ann Neurol 2008; 63: 272-287

[12] Cramer SC. Repairing the human brain after stroke: II. Restorative therapies. Ann Neurol 2008; 63: 549-560

[13] Seitz RJ. Neurology in Europe. In: Runehov ALC, Oviedo L, Azari NP.eds. Encyclopedia of sciences and religions. Springer Reference; 2013: Vol 3: $1489-1493$

[14] G-DRG System. Institut für Entgeltsystem im Krankenhaus. 2017; http://www.g-drg.de/

[15] Field MJ, Lohr KN. Guidelines for Clinical Practice: From development to use. Washington DC: National Academic Press; 1992

[16] Hendriks HJM, Van Ettekoven H, Van der Wees PJ et al. Eindverslag van het project centrale richtlijnen in de fysiotherapie. Deel 1: Achtergronden en evaluatie van het project [Final Report of the National Guidelines on Physiotherapy Project. Part 1: Backgrounds and Evaluation of the Project]. Amersfoort; Utrecht: Koninklijk Nederlands Genootschap Voor Fysiotherapie, Nederlands Paramedisch Instituut, Kwaliteitsinstituut Voor Gezondheidszorg CBO; 1998

[17] Woolf SH, Grol R, Hutchinson A et al. Clinical guidelines: Potential benefits, limitations, and harms of clinical guidelines. BMJ 1999; 318 : 527-530

[18] Visser D, Elvers H, Oostendorp RAB. Vakbekwaam en wetenschappelijk verantwoord handelen, haalbaar of... [Acting professionally and evidence based, is it achievable or... ]. Issue 2001; 2: 2-4

[19] Grol R. Invoeren van veranderingen in de praktijk [Introducing changes into practice].. In: Grol R, Wensing M, eds. Implementatie, effectieve verandering in de patiëntenzorg [Implementation, Effective Changes in Patient Care]. 2nd ed. Maarssen: Elsevier gezondheidszorg; 2001: p 25-37

[20] Campbell SM, Braspenning ], Hutchinson A et al. Research methods used in developing and applying quality indicators in primary care. Qual Saf Health Care 2002; 11: 358-364

[21] http://www.cochrane.de/de/leitlinien

[22] Tinetti ME. Performance-oriented assessment of mobility problems in elderly patients. J Am Geriatr Soc 1986; 34: 119-126

[23] de Morton NA, Davidson M, Keating JL. The de Morton Mobility Index (DEMMI): An essential health index for an ageing world. Health Quality Life Outcomes 2008; 6: 63
[24] Dohle C, Quintern J, Saal S et al. ReMoS-Arbeitsgruppe: S2e-Leitlinie Rehabilitation der Mobilität nach Schlaganfall (ReMoS). Neurol Rehabil 2015; 7: 355-494; http://www.dgnr.de/images/pdf/leitlinien/S2e_ Leitlinie_Rehabilitation_der_Mobilitaet_nach_Schlaganfall.pdf

[25] Van Peppen RPS, Kwakkel G, Harmeling-van der Wel BC et al KNGF Clinical Practice Guideline for physical therapy in patients with stroke. Review of the evidence [Translation 2008]. Ned Tijdschr v Fysioth 2004; 114: (Suppl 5): 1-78

[26] Adler ], Malone D. Early mobilization in the intensive care unit: A systematic review. Cardiopulm Phys Ther J 2012; 23: 5-13

[27] Sommers ], Engelbert RHH, Dettling-Ihnenfeldt D et al Physiotherapy in the intensive care unit: an evidence-based, expert driven, practical statement and rehabilitation recommendations. Clin Rehab 2015; 1-13 doi:10.1177/0269215514567156

[28] Seidel G, Eggers LKücken et al Prognosefaktoren in der Frührehabilitation nach schwerem Schlaganfall. Akt Neurol 2016; 43: 541-547

[29] Peschke D, Schnizer S, Kuhemey A et al. Physio- and occupational therapy pathways of stroke patients and stroke mortality. Rehabilitation 2014; 53: 224-229

[30] Bernhardt ], Churilov L, Ellery F et al. Prespecified dose-response analysis for A Very Early Rehabilitation Trial (AVERT). Neurology 2016; 86: 2138-2145

[31] Billinger SA, Arena R, Bernhardt ] et al. Physical activity and exercise recommendation for stroke survivors. A statement for healthcare professionals from the American Heart Association/American Stroke Association. Stroke 2014; 45: 2532-2553

[32] Sullivan JE, Corwner BE, Kluding PM et al. Outcome measures for individuals with stroke: process and recommendations from the American Physical Therapy Association Neurology Section Task Force. Phys Ther 2013; 93: 1383-1396

[33] Quinn T], Paolucci S, Sunnerhagen KS et al. Evidence-based stroke rehabilitation: an expanded guidance document from the European Stroke Organization (ESO) guidelines for management of ischaemic stroke and transient ischaemic attack 2008. J Rehabil Med 2009; 41: 99-111

[34] Lang CE, Strube M], Bland MD et al. Dose response of task-specific upper limb training in people at least 6 months poststroke: A phase II, single-blind, randomized, controlled trial. Ann Neurol 2016; 80: 342-354

[35] Clarke CE, Patel S, Ives $\mathrm{N}$ et al. Physiotherapy and occupational therapy versus no therapy in mild to moderate Parkinson's disease. A randomized clinical trial. JAMA Neurol 2016; 73: 291-299

[36] Nielsen G, Stone J, Matthews A et al. Physiotherapy for functional motor disorders: A consensus recommendation. J Neurol Neurosurg Psychiatr 2015; 86: 1113-1119

[37] Hesse S. Gait training after stroke: A critical appraisal. Ann Readapt Med Phys 2006; 49: 621-624

[38] Kwakkel G, Wagenaar RC, Twisk JW et al. Intensity of leg and arm training after primary middle-cerebral-artery stroke: A randomised trial. Lancet 1999; 354: 191-196

[39] Cameirão MS, Badia SB, Oller ED et al. Neurorehabilitation using the virtual reality based Rehabilitation Gaming System: Methodology, design, psychometrics, usability and validation. J Neuroeng Rehabil 2010; 7: 48

[40] Seitz RJ, Kammerzell A, Samartzi M. Monitoring of visuomoto coordination in healthy subjects and patients with stroke and Parkinson's disease: An application study using the PABLO-device. Int ] Neurorehab 2014; 1,2: 1-8 doi:doi.org/10.4172/ijn.1000113

[41] Seitz RJ, Donnan GA. Recovery potential after acute stroke. Frontiers Neurol 2015; 6: 238 doi:10.3389/fneur.2015.00238

[42] Floel A, Nagorsen U, Werhahn KJ et al. Influence of somatosensory input on motor function in patients with chronic stroke. Ann Neurol 2004; 56: 206-212 
[43] Binkofski F, Seitz R], Hackländer T et al. The recovery of motor functions following hemiparetic stroke: A clinical and MR-morphometric study. Cerebrovasc Dis 2001; 11: 273-281

[44] Matyas TA, Greenewood KM. Visual analysis of single-case time series: effects of variability, serial dependence, and magnitude of intervention effects. J Appl Behav Analysis 1990; 23: 341-351

[45] Sommers ], Vredeveld T, Lindeboom R et al. de Morton mobility index is feasible, reliable, and valid in patients with critical illness. Phys Ther 2016; 96: 1658-1666

[46] Prasad K. The Glasgow Coma Scale: a critical appraisal of its clinimetric properties. J Clin Epidemiol 1996; 49: 755-763

[47] Lam B, Middleton LE, Masellis M et al. Criterion and convergent validity of the Montreal cognitive assessment with screening and standardized neuropsychological testing. J Am Geriatr Soc 2013; 61: 2181-2185

[48] Blackburn M, van Vliet P, Mockett SP. Reliability of measurements obtained with the modified Ashworth scale in the lower extremities of people with stroke. Phys Ther 2002; 82: 25-34
[49] Lee Y, An S, Lee G. Clinical utility of the modified trunk impairment scale for stroke survivors. Disabil Rehabil 2017; 7: 1-6

[50] Schlenstedt C, Brombacher S, Hartwigsen G et al. Comparison of the Fullerton Advanced Balance Scale, Mini-BESTest, and Berg Balance Scale to Predict Falls in Parkinson Disease. Phys Ther 2016; 96: 494-501

[51] Wolf SL, Catlin PA, Gage K et al. Establishing the reliability and validity of measurements of walking time using the Emory Functional Ambulation Profile. Phys Ther 1999; 79: 1122-1133

[52] Goetz CG, Fahn S, Martinez-Martin P et al. Movement Disorder Society-sponsored revision of the Unified Parkinson's Disease Rating Scale (MDS-UPDRS): Process, format, and clinimetric testing plan. Mov Disord 2007; 22: 41-47

[53] Doig E, Fleming J, Kuipers $P$ et al. Clinical utility of the combined use of the Canadian Occupational Performance Measure and Goal Attainment Scaling. Am J Occup Ther 2010; 64: 904-914 